\title{
PHOTOELECTRON SPECTROSCOPY OF MASS-SELECTED COPPER-WATER CLUSTER NEGATIVE IONS
}

\author{
FUMINORI MISAIZU, KEIZO TSUKAMATO, MASAOMI SANEKATA and \\ KIYOKAZU FUKE
}

\author{
Institute for Molecular Science and The Graduate University for Advanced \\ Studies, Myodaiji, Okazaki 444, Japan
}

(Received 12 April, 1994)

\begin{abstract}
Negative-ion photoelectron spectroscopy has been applied in order to obtain size dependent information about the electronic structure of clusters of metal atoms solvated with polar molecules. In the present paper we have investigated the photoelectron spectra of $\mathrm{Cu}^{-}\left(\mathrm{H}_{2} \mathrm{O}\right)_{n}$ cluster ions with $n=0-4$ and also those of $\mathrm{Cu}_{2}{ }^{-}\left(\mathrm{H}_{2} \mathrm{O}\right)_{n}$ with $n=0$ and 1 . In the spectra of $\mathrm{Cu}^{-}\left(\mathrm{H}_{2} \mathrm{O}\right)_{n}$, the lowest energy bands were assigned to the electron detachment from the $\mathrm{CuOH}^{-}\left(\mathrm{H}_{2} \mathrm{O}\right)_{n-1}$ which were produced in the source together with the above cluster ions. The observed bands for $\mathrm{Cu}^{-}\left(\mathrm{H}_{2} \mathrm{O}\right)_{n}$ were all assigned to the transitions to the states originating in the ground ${ }^{2} S$ and first excited ${ }^{2} D$ states of the $\mathrm{Cu}$ atom. The stepwise hydration for $\mathrm{Cu}^{-}$and $\mathrm{Cu}_{2}^{-}$was discussed from the observed spectral shifts.
\end{abstract}

KEY WORDS: Photoelectron spectroscopy, Clusters, Solvated metal atom, Copper, Hydration

\section{INTRODUCTION}

Electronic structure of the clusters with one metal atom solvated by polar molecules has been one of the central interests for many researchers for the purpose of unveiling the microscopic aspect of the bulk electrolyte solution. In particular, the electronic states having an ion-pair character in the clusters with an alkali metal atom or an alkaline-earth metal ion ligated by polar solvent molecules such as $\mathrm{H}_{2} \mathrm{O}$ and $\mathrm{NH}_{3}$ have been investigated both experimentally ${ }^{1-10}$ and theoretically. ${ }^{11-19}$ Characterization of the ion-pair state in which an electron of the metal atom is delocalized over the solvent molecules with increasing number of ligands may provide microscopic information on the solvation process of a metal atom/ion in bulk liquid. In the case of alkaline-earth metal ion-solvent systems, stabilization of the ion-pair state as a function of the cluster size was examined by photodissociation spectroscopy. ${ }^{1-7}$ Especially for $\mathrm{Sr}^{+}\left(\mathrm{NH}_{3}\right)_{n}$, Farrar and his coworkers discussed the possibility of a Rydberg-type ion-pair state from the large redshift of the absorption band. ${ }^{1-4}$ The photodissociation of $\mathrm{Mg}^{+}\left(\mathrm{H}_{2} \mathrm{O}\right)_{n}$ clusters was also investigated by the present authors, ${ }^{5-7}$ and some clues of the ion-pair state have been obtained for this system. 
As for the neutral alkali atom-ligand systems, the information about the excited electronic states with charge-transfer character was obtained from the ionization potential (IP) measurement only indirectly so far. IPs of $\mathrm{Na}\left(\mathrm{H}_{2} \mathrm{O}\right)_{n}$ and $\mathrm{Na}\left(\mathrm{NH}_{3}\right)_{n}$ were measured by Hertel and his coworkers ${ }^{8,9}$ and those of $\mathrm{Cs}\left(\mathrm{H}_{2} \mathrm{O}\right)_{n}$ and $\mathrm{Cs}\left(\mathrm{NH}_{3}\right)_{n}$ were determined by the authors. ${ }^{10}$ Both of the $\mathrm{Na}$ and $\mathrm{Cs}$ systems were found to have similar features: For the metal- $\mathrm{H}_{2} \mathrm{O}$ systems, IP decreases monotonously with increasing $n$ up to 4 , however, it becomes constant for $n \geq 5$ at a value which coincides with the photoelectric threshold of bulk ice. In contrast, the IP of the metal- $\mathrm{NH}_{3}$ system decreases linearly with increasing cluster radius for $n$ up to 30 and the limiting value again coincides with the estimated IP of an excess electron solvated in liquid ammonia. These results can be explained by the stabilization of the ion-pair state with increasing number of water molecules: Such state is considered to become the ground state for $(\mathrm{Na}, \mathrm{Cs})-\left(\mathrm{H}_{2} \mathrm{O}\right)_{n}$ clusters with $n \approx 4$, whereas more ligands are necessary to stabilize the state for $(\mathrm{Na}, \mathrm{Cs})-\left(\mathrm{NH}_{3}\right)_{n}$ systems. However, an alternative interpretation for these results has been proposed theoretically. ${ }^{19}$ It is informative to obtain more decisive data about the electronic structures of the solvated alkali metal clusters.

Photoelectron spectroscopy (PES) of negative ion clusters is one of the most powerful method to get information not only on the stability of the negative ions but also on the electronic structure of the neutral clusters. This method was applied to various gas phase clusters in the past decade. Recently, Cheshnovsky and his coworkers reported the photoelectron spectra of the cluster negative ions of halogen atom solvated with $\mathrm{H}_{2} \mathrm{O}, \mathrm{CO}_{2}$, and $\mathrm{NH}_{3}$ molecules. ${ }^{20-22}$ In the photoelectron spectrum of $\mathrm{Cl}^{-}\left(\mathrm{NH}_{3}\right)$, they assigned a broad band peaked at $6.45 \mathrm{eV}$ binding energy to be the transition to a charge-transfer (CT) state, $\mathrm{Cl}^{-} \mathrm{NH}_{3}{ }^{+} .{ }^{22} \mathrm{As}$ far as we know, this is the only species that the CT state was observed in the photoelectron spectrum, though electron transfers from the ligand to the solute atom in this system.

In this paper we report the PES results of the negative ions of copper-water clusters. The coinage metal atoms, $\mathrm{Cu}, \mathrm{Ag}$, and $\mathrm{Au}$, have electronic configurations of ${ }^{2} S\left((n-1) d^{10} n s^{1}\right)$ in its ground state and thus have electronic characters analogous to the alkali metal atoms. They also have positive electron affinities because of the stabilization of the negative ions as a result of the $n$ s shell closing with addition of an excess electron. Therefore we investigated the $\mathrm{Cu}$-water systems for the reasons both of testing the performance of the newly developed photoelectron spectrometer and of investigating the metal-water systems analogous to the hydrated alkali metal clusters. We have obtained the photoelectron spectra of $\mathrm{Cu}^{-}\left(\mathrm{H}_{2} \mathrm{O}\right)_{n}(n=0-4)$ and $\mathrm{Cu}_{2}{ }^{-}\left(\mathrm{H}_{2} \mathrm{O}\right)_{n}(n=0$ and 1). Some of the lower-energy bands observed in the spectra are assigned to the electron detachment from the $\mathrm{CuOH}^{-}\left(\mathrm{H}_{2} \mathrm{O}\right)_{n}$ ions produced simultaneously with the above ions. The observed bands for $\mathrm{Cu}^{-}\left(\mathrm{H}_{2} \mathrm{O}\right)_{n}$ are all assigned to the transitions to the neutral states derived from the ${ }^{2} S\left(3 d^{10} 4 s^{1}\right)$ and ${ }^{2} D\left(3 d^{9} 4 s^{2}\right)$ levels of the free $\mathrm{Cu}$ atom. The successive hydration energies of $\mathrm{Cu}^{-}\left(\mathrm{H}_{2} \mathrm{O}\right)_{n}$ in these states are found to be almost constant for the $n$ range examined in this study and are discussed in line with the PES results of the hydrated halogen atom clusters. Stabilization of each band observed in the photoelectron spectrum of $\mathrm{Cu}_{2}{ }^{-}$by hydration is also discussed in comparison with those of the hydrated $\mathrm{Cu}^{-}$clusters. 


\section{EXPERIMENTAL}

Three-stage differentially evacuated chambers were constructed for the photoelectron spectroscopy of the negative ions. They consist of a negative ion beam source, timeof-flight (TOF) mass spectrometer, and a magnetic-bottle photoelectron spectrometer as shown in Fig. 1. Negatively-charged ions of copper-water clusters were produced by a laser vaporization. The details of the cluster source were similar to those of the cluster positive ions which were presented in the previous papers. ${ }^{5,6}$ Second harmonic of a Nd:YAG laser (Continuum, YG661) was focused on to the copper rod $(\phi 3 \mathrm{~mm})$ which was rotating and translating in an aluminum block. Helium gas of $2 \mathrm{~atm}$ mixed with water vapor at room temperature was expanded through the block from a pulsed valve (General Valve, Series 9 or Model PSV, R. M. Jordan Co.). The negative ions directly produced in the source were accelerated to ca. $800 \mathrm{eV}$ in a Wiley-McLaren type TOF mass spectrometer ${ }^{23}$ by pulsed electric fields and were mass-separated in the mass spectrometer. The TOF mass spectrum of the nascently

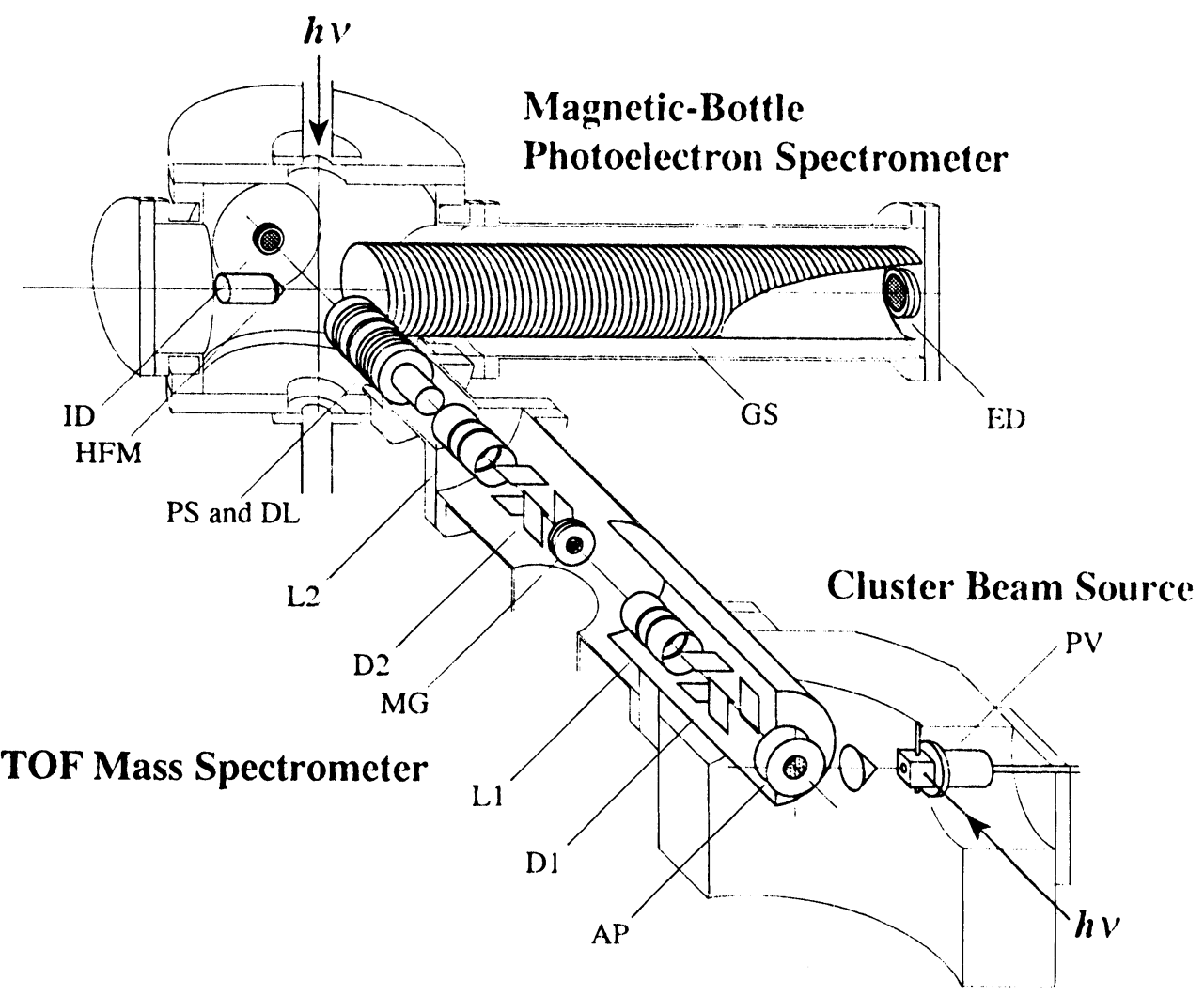

Figure 1 Schematic drawings of the experimental apparatus. PV: pulsed valve, AP: acceleration plates, D1, D2: deflectors, L1, L2: einzel lenses, MG: pulsed mass gate, PS: potential switch, DL: deceleration lenses, HFM: high field magnet, GS: guiding solenoid, ID: ion detector, ED: electron detector. 
produced negative ions was recorded by using dual microchannel plates (Hamamatsu, F1551-23S) placed at the end of the chamber. For the photoelectron kinetic energy measurement, negative ions with a given mass-to-charge ratio were selected with a pulsed mass gate after flying $50 \mathrm{~cm}$, and were decelerated to several tens of $\mathrm{eV}$ with a pulsed potential switching method. Decelerated ions were irradiated with a detachment laser at right angles in the center of the third chamber. The magnetic bottle photoelectron spectrometer was used to measure the kinetic energy of the detached electron: it has an advantage to collect almost all the electrons emitted over $4 \pi$ steradian with a magnetic field produced by a combination of a strong field magnet near the detachment zone and a weak field solenoid at the electron flight tube. ${ }^{24,25}$ The detached electrons were detected by dual microchannel plates (Hamamatsu, F1552-23S) after flying about $1.2 \mathrm{~m}$ in the flight tube. The optimized magnetic fields at the detachment region and in the flight tube were about $800 \mathrm{G}$ and $2 \mathrm{G}$, respectively, and the resolution of the photoelectron spectra was about $120 \mathrm{meV}$ for the $1.23 \mathrm{eV}$ peak of the $\mathrm{Cu}^{-}$ion with a detachment laser of $355 \mathrm{~nm}$. The electron signals were stored in a digital oscilloscope (LeCroy 7200) after amplified by a fast preamplifier (HP, 8447D). Electron counts were accumulated as a function of flight time in the oscilloscope.

Third and fourth harmonics of a Nd:YAG laser (Quanta-Ray, DCR-2A) were used for electron detachment with a typical laser fluence of ca. $5 \mathrm{~mJ} / \mathrm{cm}^{2}$. Under the detachment by fourth harmonic $(266 \mathrm{~nm}, 4.66 \mathrm{eV})$, background electron signals from the surface of the chamber cannot be negligible: The background electrons have an energy distribution peaked around $3.8 \mathrm{eV}$. Thus the photoelectron spectrum was obtained by subtracting the background spectrum from the total spectrum. The photoelectron spectra using the third harmonic $(355 \mathrm{~nm}, 3.49 \mathrm{eV})$ were also recorded for comparison with those taken by $266-\mathrm{nm}$ detachment.

\section{RESULTS AND DISCUSSION}

\subsection{Negative Ions of the Copper-Water Clusters}

Figure 2 shows a typical TOF mass spectrum of the cluster negative ions formed in the source. These ions were monitored by the microchannel plate placed at the end of the photoelectron energy analyzer chamber without using the deceleration plates and the potential switching grids. Because a $\mathrm{Cu}$ atom has a positive electron affinity, $1.23 \mathrm{eV},{ }^{26}$ stable negative atomic ions and hydrated atomic ions can be produced. Actually, two series of ion signals which can be assigned to those of ${ }^{63} \mathrm{Cu}^{-}\left(\mathrm{H}_{2} \mathrm{O}\right)_{n}$ and ${ }^{65} \mathrm{Cu}^{-}\left(\mathrm{H}_{2} \mathrm{O}\right)_{n}$ were observed in the mass spectrum. We can also discern another series of cluster ions, $\mathrm{CuOH}^{-}\left(\mathrm{H}_{2} \mathrm{O}\right)_{n-1}$, which are single unit mass smaller than the above series and thus partly superimposed on the above series. From the known isotopic abundance of $\mathrm{Cu},{ }^{63} \mathrm{Cu}:{ }^{65} \mathrm{Cu}=69.2: 30.8$, the fraction of $\mathrm{CuOH}^{-}$was estimated to be ca. $30 \%$ of that of $\mathrm{Cu}^{-}\left(\mathrm{H}_{2} \mathrm{O}\right)$. The fractions of larger $\mathrm{CuOH}^{-}\left(\mathrm{H}_{2} \mathrm{O}\right)_{n-1}$ cluster ions with respect to those of $\mathrm{Cu}^{-}\left(\mathrm{H}_{2} \mathrm{O}\right)_{n}$ were almost the same as that for $n=1$ from the shape of the TOF mass peaks, though these ions signals becomes congested each other with increasing number of water molecules. Beside the two series of cluster 


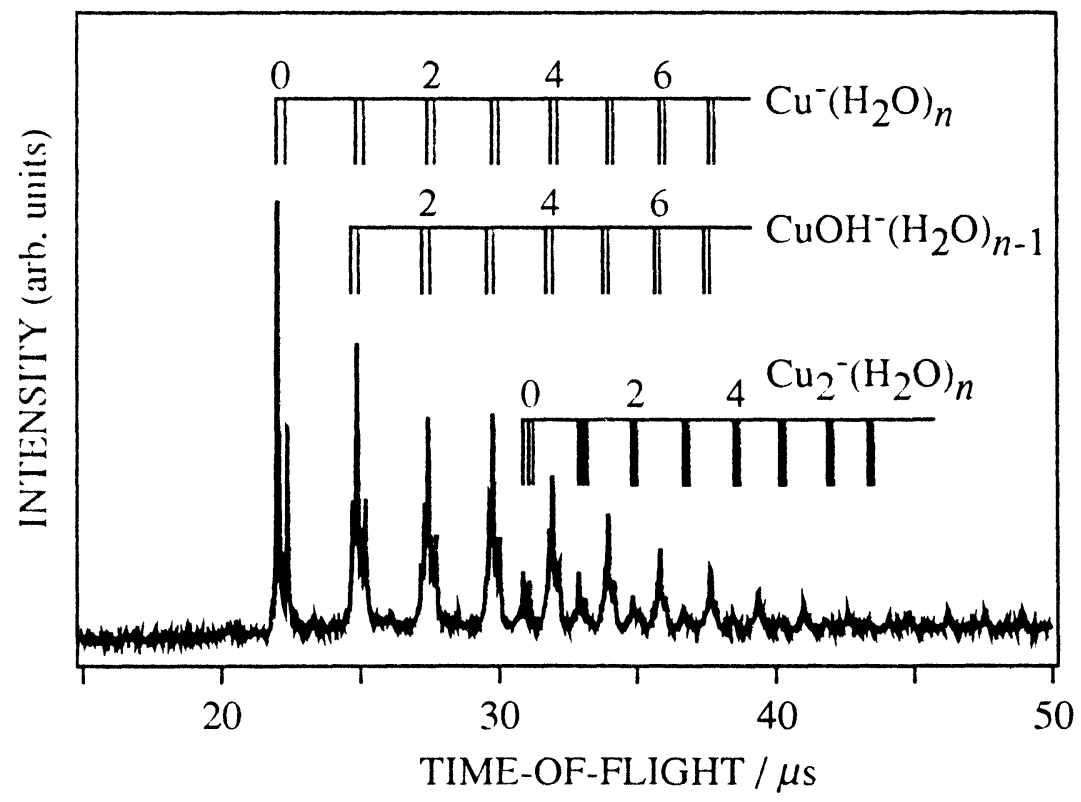

Figure 2 Typical time-of-flight mass spectrum of the negative ions of the copper-water clusters nascently produced in the source.

ions noted above, the ions of copper dimer solvated with water, $\mathrm{Cu}_{2}-\left(\mathrm{H}_{2} \mathrm{O}\right)_{n}$, also appear in the mass spectrum. Although the ions of water clusters, $\left(\mathrm{H}_{2} \mathrm{O}\right)_{m}{ }^{-}(m=n$ + 7), have the same masses as ${ }^{63} \mathrm{Cu}^{-}\left(\mathrm{H}_{2} \mathrm{O}\right)_{n}$, the fractions of the former ions are considered to be rather small for $m \leq 10$, i.e., $n \leq 3$, from the intensity of the isotopic series of the latter ions in the mass spectrum and also from the previous works on the mass spectroscopy of the $\left(\mathrm{H}_{2} \mathrm{O}\right)_{m}{ }^{-}$clusters. ${ }^{27-30}$

\subsection{Assignment of the Bands in the Photoelectron Spectra of $\mathrm{Cu}^{-}\left(\mathrm{H}_{2} \mathrm{O}\right)_{n}$}

Photoelectron spectra of $\mathrm{Cu}^{-}\left(\mathrm{H}_{2} \mathrm{O}\right)_{n}$ for $n=0-4$ detached at $266 \mathrm{~nm}$ are depicted in Fig. 3. All of the bands observed in these spectra were reproduced within an error of $0.10 \mathrm{eV}$ in the spectra obtained by $355-\mathrm{nm}$ detachment. The spectrum of $\mathrm{Cu}^{-}$(Fig. 3a) consists of an intense band at $1.23 \mathrm{eV}$ and two weak bands at 2.6 and $2.8 \mathrm{eV}$ : the first band corresponds to the transition of $\mathrm{Cu}^{2} S\left(3 d^{10} 4 s^{1}\right) \leftarrow \mathrm{Cu}^{-}{ }^{1} S\left(d^{10} s^{2}\right)$, and the remaining bands to those of $\mathrm{Cu}^{2} D_{5 / 2}\left(d^{9} s^{2}\right) \leftarrow \mathrm{Cu}^{-}{ }^{1} S$ and $\mathrm{Cu}^{2} D_{3 / 2}\left(d^{9} s^{2}\right) \leftarrow \mathrm{Cu}^{-}$ ${ }^{1} S$, respectively. This spectrum was frequently reported in the study of $\mathrm{Cu}_{n}{ }^{-}$clusters by several groups. ${ }^{31-33}$ The relative intensities of the $3 d^{-1}$ bands at 2.6 and $2.8 \mathrm{eV}$ with respect to the $4 s^{-1}$ band at $1.23 \mathrm{eV}$ are almost the same as those reported by Lineberger and his coworkers, ${ }^{31}$ though they are smaller than those reported by Cheshnovsky et al. ${ }^{32}$ and Cha et al. ${ }^{33}$

The spectra for $\mathrm{Cu}^{-}\left(\mathrm{H}_{2} \mathrm{O}\right)_{n}$ with $n=1$ and 2 exhibit more complicated feature than that of $\mathrm{Cu}^{-}$as shown in Figs. $3 \mathrm{~b}$ and $3 \mathrm{c}$. This may be due to the spectral contamina- 


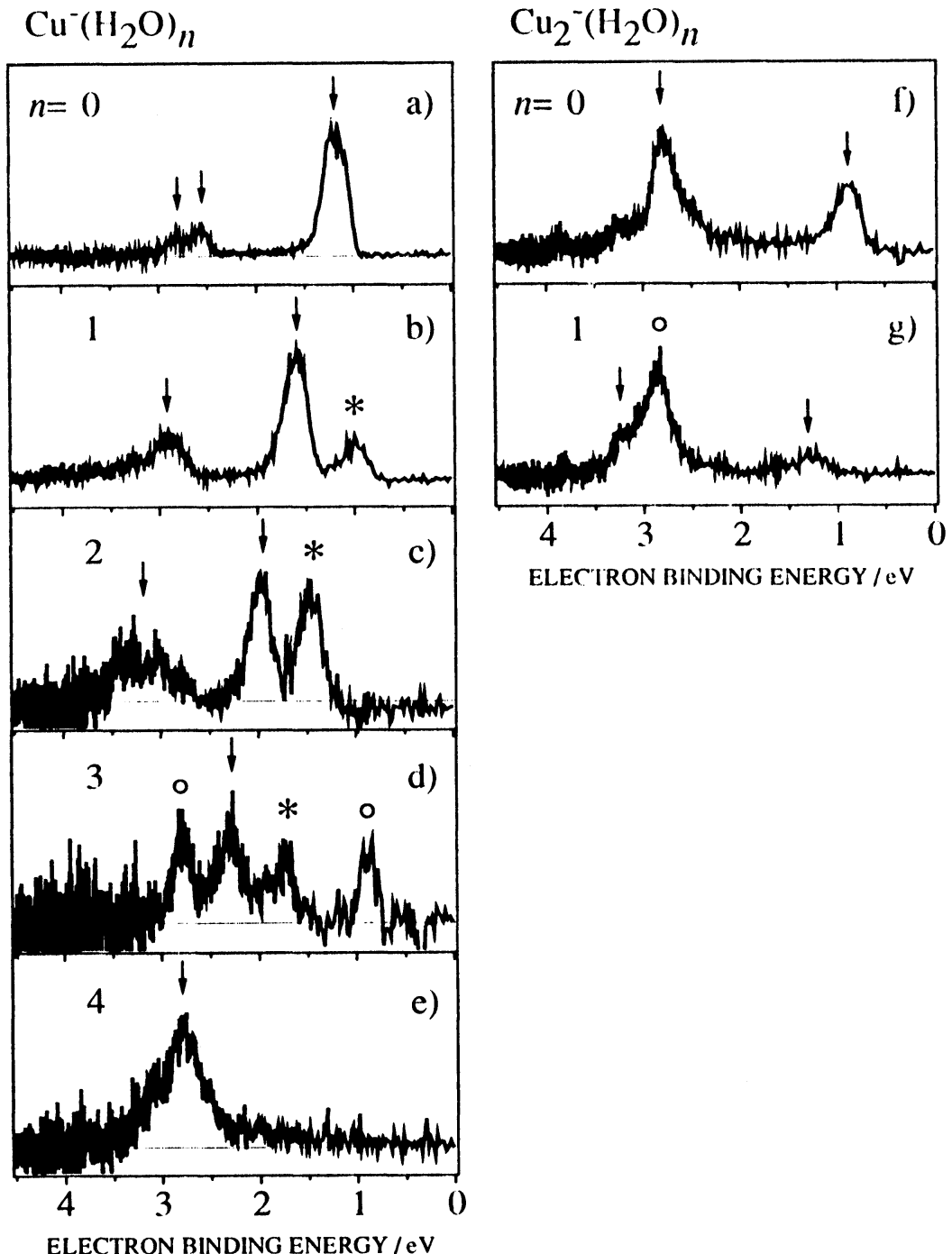

Figure 3 Photoelectron spectra of $\mathrm{Cu}^{-}\left(\mathrm{H}_{2} \mathrm{O}\right)_{n}(n=0-4)$ and $\mathrm{Cu}_{2}{ }^{-}\left(\mathrm{H}_{2} \mathrm{O}\right)_{n}(n=0$ and 1) with detachment at $266 \mathrm{~nm}(4.66 \mathrm{eV})$. Asterisks in b)-d) show the bands from the $\mathrm{CuOH}^{-}\left(\mathrm{H}_{2} \mathrm{O}\right)_{n}$ ions. For the spectra of $\mathrm{Cu}^{-}\left(\mathrm{H}_{2} \mathrm{O}\right)_{3}(\mathrm{~d})$ and $\mathrm{Cu}_{2}^{-}\left(\mathrm{H}_{2} \mathrm{O}\right)(\mathrm{g})$, the bands from coexisting ions which were not discriminated by pulsed mass gate are shown by circles (see text).

tion by $\mathrm{CuOH}^{-}\left(\mathrm{H}_{2} \mathrm{O}\right)_{n-1}$. As for $n=1$, the relative intensity of $\mathrm{CuOH}^{-}$was estimated to be ca. $30 \%$ of $\mathrm{Cu}^{-}\left(\mathrm{H}_{2} \mathrm{O}\right)$ from the mass spectrum. Since the $\mathrm{CuOH}^{-}\left(\mathrm{H}_{2} \mathrm{O}\right)_{m-1}$ ions are only single unit mass smaller than $\mathrm{Cu}^{-}\left(\mathrm{H}_{2} \mathrm{O}\right)_{n}$, we could not discriminate them by the pulsed mass gate. We also measured the spectra with various timings of the detachment-laser irradiation after decelerating the ions. However, the features of the spectra did not change substantially. This is because the ions diffuse spatially after 
deceleration. On the other hand, the relative intensities of the lowest energy bands in the spectra for $n=1$ and 2 (indicated by asterisks in Fig. 3) are found to be much more sensitive to the source conditions, especially to the fluence of the vaporization laser, than those of the higher energy bands. In the production of the $\mathrm{CuOH}^{-}\left(\mathrm{H}_{2} \mathrm{O}\right)_{n}$ ions, it is expected that extra photons may be needed to dissociate the water molecule. Although the EA value of $\mathrm{CuOH}^{-}$is not reported so far both experimentally and theoretically, it is considered to be positive because the stable negative ions with a lifetime longer than the flight time in the mass spectrometer, several tens of $\mu \mathrm{s}$, were observed in the TOF mass spectrum. It is also expected that the $\mathrm{EA}$ of $\mathrm{CuOH}$ is not so large though it is a positive value from the following reasons. In the neutral $\mathrm{CuOH}$, the covalent bond is expected to be formed between the $4 \mathrm{~s}$ electron of the metal and the open shell $\pi$ electron on the $\mathrm{OH}$, yielding a ' $\mathrm{A}$ ' state in $C_{s}$ symmetry. Because of the large EA of $\mathrm{OH}(1.83 \mathrm{eV})^{26,34,35}$ and the small ionization potential (IP) of $\mathrm{Cu}(7.72 \mathrm{eV}),{ }^{36}$ this bond is expected to be polarized toward the $\mathrm{OH}$. Recent results on the spectroscopic ${ }^{37,38}$ and theoretical studies ${ }^{39,40}$ support this expectation: The ground state $\left({ }^{\prime} \mathrm{A}^{\prime}\right)$ geometry of the $\mathrm{CuOH}$ has a $C_{s}$ symmetry with $\mathrm{Cu}-\mathrm{O}-\mathrm{H}$ angle of $110-111^{\circ}$, which is close to that of $\mathrm{H}_{2} \mathrm{O}\left(105^{\circ}\right)$. This result suggests a substantial contribution of the covalency to the $\mathrm{Cu}-\mathrm{OH}$ bonding in $\mathrm{CuOH}$. Furthermore, Mulliken population analysis shows that the ionic character of $\mathrm{Cu}^{+}-\mathrm{OH}^{-}$is also included in the bonding. ${ }^{40}$ In contrast, the excess electron in $\mathrm{CuOH}^{-}$is probably in the antibonding orbital and makes the $\mathrm{Cu}-\mathrm{OH}$ bonding weaker than in the neutral. Therefore the EA of $\mathrm{CuOH}$ is expected to be smaller than that of $\mathrm{Cu}$. On the basis of these arguments, we have concluded that the lowest energy peaks observed in Figs. $3 \mathrm{~b}$ and $3 \mathrm{c}$ are ascribed to the photoelectron from $\mathrm{CuOH}^{-}$and $\mathrm{CuOH}^{-}\left(\mathrm{H}_{2} \mathrm{O}\right)$. The rest of the bands observed in the photoelectron spectra of $\mathrm{Cu}^{-}\left(\mathrm{H}_{2} \mathrm{O}\right)$ and $\mathrm{Cu}^{-}\left(\mathrm{H}_{2} \mathrm{O}\right)_{2}$ are all assigned to the transitions originating from the $\mathrm{Cu}^{2} S \leftarrow \mathrm{Cu}^{-} S$ and $\mathrm{Cu}^{2} D \leftarrow \mathrm{Cu}^{-} S$ ones as discussed in the next section.

The PES results of $\mathrm{Cu}^{-}\left(\mathrm{H}_{2} \mathrm{O}\right)_{3}$ are found to be more complicated than those for $n=1$ and 2 as shown in Fig. $3 \mathrm{~d}$. The observed spectrum has bands peaked at 0.88 , $1.71,2.28$, and $2.79 \mathrm{eV}$. The band at $1.71 \mathrm{eV}$ is attributed to the electron detachment from $\mathrm{CuOH}^{-}\left(\mathrm{H}_{2} \mathrm{O}\right)_{2}$ in accordance with the previous discussions. The complexity of the spectrum is also due to the incapability of mass selection of $\mathrm{Cu}^{-}\left(\mathrm{H}_{2} \mathrm{O}\right)_{3}$ from other ions in the pulsed mass gate: The detachment signals from the $\mathrm{Cu}_{2}{ }^{-}$ions $(\mathrm{m} / \mathrm{z}$ $=126,128$ and 130) are included in addition to those from $\mathrm{Cu}^{-}\left(\mathrm{H}_{2} \mathrm{O}\right)_{3}(\mathrm{~m} / z=117$ and 119) in this spectrum. Since the photoelectron spectrum of $\mathrm{Cu}_{2}{ }^{-}$consists of two bands at 0.92 and $2.73 \mathrm{eV}$ as shown in Fig. 3f, the bands at 0.88 and $2.79 \mathrm{eV}$ observed in the spectrum are ascribed to the detachment from $\mathrm{Cu}_{2}{ }^{-}$. Therefore, the band at $2.28 \mathrm{eV}$ can be assigned to the detachment from $\mathrm{Cu}^{-}\left(\mathrm{H}_{2} \mathrm{O}\right)_{3}$, which corresponds to the transition to the neutral cluster state derived from the ${ }^{2} S$ state of the $\mathrm{Cu}$ atom. We could not observe the band originating from the transition to the ${ }^{2} D$ state, probably due to the large background signal.

The spectrum of $\mathrm{Cu}^{-}\left(\mathrm{H}_{2} \mathrm{O}\right)_{4}$ exhibits a band peaked at $2.77 \mathrm{eV}$ as shown in Fig. $3 e$. In contrast to the case for $n=1-3$, no band assignable to the detachment from $\mathrm{CuOH}^{-}\left(\mathrm{H}_{2} \mathrm{O}\right)_{3}$ is observed. The observed band at $2.77 \mathrm{eV}$ is also assignable to the detachment from $\mathrm{Cu}_{2}-\left(\mathrm{H}_{2} \mathrm{O}\right)$, because the band having the similar spectral feature is 
also observed in the $\mathrm{Cu}_{2}{ }^{-}\left(\mathrm{H}_{2} \mathrm{O}\right)$ spectrum as shown in Fig. 3g. However, this possibility is excluded because of the missing of the lower energy band at $1.28 \mathrm{eV}$ of $\mathrm{Cu}_{2}-\left(\mathrm{H}_{2} \mathrm{O}\right)$ in the $\mathrm{Cu}^{-}\left(\mathrm{H}_{2} \mathrm{O}\right)_{4}$ spectrum. Therefore, the band at $2.77 \mathrm{eV}$ is believed to be mostly due to the detachment from $\mathrm{Cu}^{-}\left(\mathrm{H}_{2} \mathrm{O}\right)_{4}$.

\subsection{Hydration of $\mathrm{Cu}\left({ }^{2} \mathrm{~S}\right.$ and $\left.{ }^{2} \mathrm{D}\right)$ and $\mathrm{Cu}^{-}\left({ }^{I} \mathrm{~S}\right)$}

Figure 4 depicts the vertical detachment energies (VDEs), derived from the peak positions of the photoelectron spectra, for all ions examined here. Lowest energy transitions are attributed to the photoelectron detachment from $\mathrm{CuOH}^{-}\left(\mathrm{H}_{2} \mathrm{O}\right)_{n}$ as discussed above. Higher two series of the bands are attributed to the transitions for $\mathrm{Cu}^{-}\left(\mathrm{H}_{2} \mathrm{O}\right)_{n}$ : The first series of transition shows the lowest VDEs of the electron which originates from the $4 s$ orbital of the $\mathrm{Cu}^{-}$in $\mathrm{Cu}^{-}\left(\mathrm{H}_{2} \mathrm{O}\right)_{n}$. The VDEs were found to increase monotonically with increasing number of water molecules: The average stabilization energy with an increase of one water molecule is determined to be ca. $0.38 \mathrm{eV}$ from this figure. It is also noted that the bandwidths of the series are almost constant $(\approx 300 \mathrm{meV})$ up to $n=3$. These results seem to imply that the excess electron in the cluster is localized on the $\mathrm{Cu}$ atom at least up to $n=4$ in the ground state, and the successive solvation by water results simply in the stabilization of the states. This conclusion is consistent with the fact that the EA of the $\mathrm{Cu}$ atom is positive $(1.23 \mathrm{eV})^{34,35}$ whereas those of the water clusters, $\left(\mathrm{H}_{2} \mathrm{O}\right)_{n}$, with $n<6$ are negative except for $n=2(\leq 0.1 \mathrm{eV})$ from the PES study of $\left(\mathrm{H}_{2} \mathrm{O}\right)_{n}{ }^{-} .{ }^{41}$ We have also observed

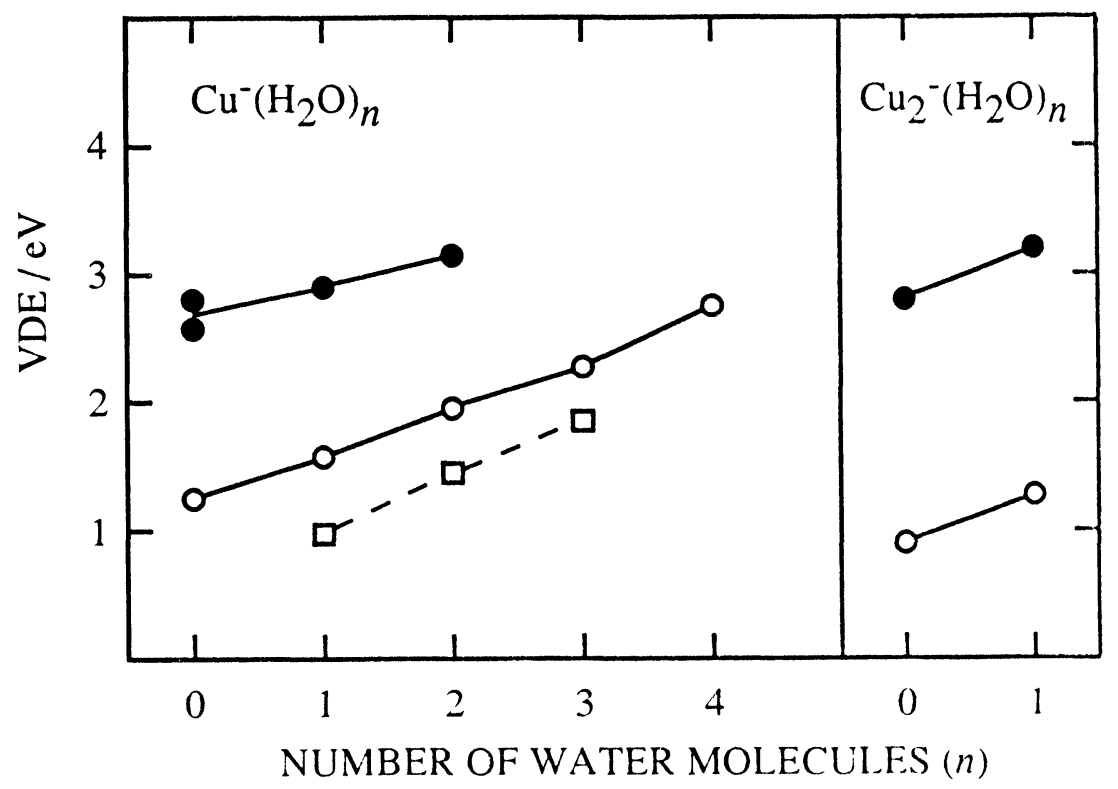

Figure 4 Vertical detachment energies (VDEs) of the electron for the neutral ground (open circles) and the excited states (filled circles) as a function of the number of solvent water molecules for $\mathrm{Cu}^{-}$ and $\mathrm{Cu}_{2}^{-}$. The VDEs for $\mathrm{CuOH}^{-}\left(\mathrm{H}_{2} \mathrm{O}\right)_{n-1}$ are also shown by squares. 
the secondarily lowest VDEs which originate from the $3 d$ electron of $\mathrm{Cu}^{-}$up to $n=2$. Though the $3 d$ electron detachment from $\mathrm{Cu}^{-}$produces two spin-orbit states of $\mathrm{Cu},{ }^{2} D_{5 / 2}$ and ${ }^{2} D_{3 / 2}$, as seen in Fig. 3a, we cannot discern these states for $n=1$ and 2 because of the broadening of the band. This is probably due to the structural difference between the excited states and the negative ions and also due to the congestion of the vibrational modes. This series also shows a linear dependence upon the stepwise hydration. The energy increase for this series is determined to be ca. $0.2 \mathrm{eV}$ per water molecule.

From the above VDEs of $\mathrm{Cu}^{-}\left(\mathrm{H}_{2} \mathrm{O}\right)_{n}$, we estimated the successive hydration energies for the anion states and the ${ }^{2} D$ excited states. Unfortunately, there is no experimental and theoretical data on the hydration energy of the neutral $\mathrm{Cu}\left(\mathrm{H}_{2} \mathrm{O}\right)_{n}$, except for that of $\mathrm{Cu}\left(\mathrm{H}_{2} \mathrm{O}\right)$ calculated by Bauschlicher. ${ }^{42}$ Thus we adopted the theoretical result $(0.2 \mathrm{eV})$. According to his calculations, the bonding between the metal and a water molecule involves the electrostatic interaction arising from the penetration of the ligand dipole into the metal charge cloud. This bonding is enhanced by the polarization of the $4 s$ away from the ligand lone pair and by the polarization of the ligand. We also tentatively assumed that the hydration energies for $\mathrm{Cu}\left(\mathrm{H}_{2} \mathrm{O}\right)_{n}$ are the same with that for $\mathrm{Cu}$. The results are summarized in Fig. 5.

As for the ${ }^{2} D$ excited state of $\mathrm{Cu}$, the successive hydration energy is found to be ca. $0.3 \mathrm{eV}$, which is slightly larger than that of the neutral ground state. The difference in hydration energy for these states is qualitatively explained as follows. Because of the electronic configuration of $3 d^{9} 4 s^{2}$ in the ${ }^{2} D$ state of $\mathrm{Cu}$, it seems that the repulsive interaction between the diffuse $4 s$ electrons and the ligand lone pair may be larger

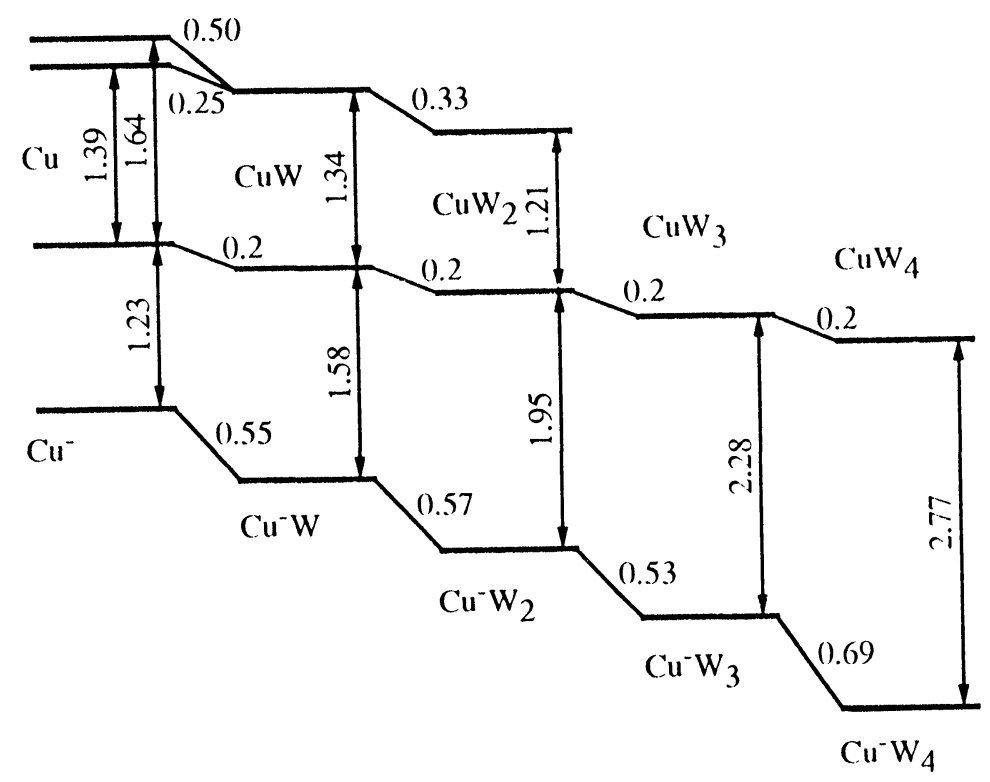

Figure 5 Energy diagram of the neutral $\mathrm{Cu}\left(\mathrm{H}_{2} \mathrm{O}\right)_{n}$ and the $\mathrm{Cu}^{-}\left(\mathrm{H}_{2} \mathrm{O}\right)_{n}$ clusters ions. Water molecules are designated by $\mathrm{W}$. All values are shown in $\mathrm{eV}$. 
than that in the ground state in which one electron is in the compact $3 d$ orbital. However, when the electron density of the $3 d \sigma$ orbital is reduced in the excited state, binding energy between the metal and the ligand may increase as a result of reduced nuclear shielding for the $\mathrm{H}_{2} \mathrm{O}$ lone pair electrons due to the one less electron along the internuclear axis.

The hydration energies of the $\mathrm{Cu}^{-}\left(\mathrm{H}_{2} \mathrm{O}\right)_{n}, n=0-4$, are found to be almost constant, $\approx 0.6 \mathrm{eV}$, as shown in Fig. 5. These results indicate that the first solvation shell around the $\mathrm{Cu}^{-}$ion is not still filled at $n=3$. It is informative to compare these results with those of the hydrated halide negative ions, $\mathrm{X}^{-}\left(\mathrm{H}_{2} \mathrm{O}\right)_{n}\left(\mathrm{X}=\mathrm{Cl}, \mathrm{Br}\right.$ and I), ${ }^{20,21,43-45}$ which were the only hydrated atomic negative ions investigated extensively by both experimentally and theoretically. The successive hydration energies were determined by high-pressure mass spectrometry ${ }^{43,44}$ and recently by photoelectron spectroscopy. ${ }^{20,21}$ According to the results, the binding energies of the halide ions with a water molecule were determined to be $0.57^{43}$ and $0.65^{20,44}$ for $\mathrm{Cl}^{-}, 0.55^{43}$ and $0.57^{20}$ for $\mathrm{Br}^{-}$, and $0.44,{ }^{43} 0.48,{ }^{44}$ and $0.45 \mathrm{eV}^{20}$ for $\mathrm{I}^{-}$, respectively. The simplest view of the interaction between $\mathrm{X}^{-}$and $\mathrm{H}_{2} \mathrm{O}$ would be the electrostatic one between the excess electron on the halogen atom and the dipole of the ligand. The energy of this interaction is inversely proportional to the distance between the halide ion and the dipole. In fact, the crystal ionic radii of the ions, 1.81 for $\mathrm{Cl}^{-}, 1.96$ for $\mathrm{Br}^{-}$, and $2.20 \AA$ for $\mathrm{I}^{-46}$ are qualitatively consistent with the order of the determined hydration energies for the three halide negative ions. As for the $\mathrm{Cu}^{-}$ion, ionic radius has not been reported so far. However, assuming a correlation between the ionic radii and the van der Waals radii, the ionic radius of $\mathrm{Cu}^{-}$was slightly smaller than the above three halide negative ions. ${ }^{47}$ The hydration energy of ca. $0.6 \mathrm{eV}$ for $\mathrm{Cu}^{-}$is qualitatively explained by this simple electrostatic consideration.

The equilibrium structures and the hydration energies for the hydrated halide ions are also predicted theoretically. ${ }^{45}$ The calculated successive hydration energies are in good agreement with those determined experimentally. ${ }^{20,21,43,44}$ According to these studies, hydrogen bonding has found to contribute considerably to the interaction between the ion and the water molecule in addition to the electrostatic interaction noted above. In the optimized structure for $\mathrm{X}^{-}\left(\mathrm{H}_{2} \mathrm{O}\right)$, the ion interacts most strongly with one of the hydrogen atoms of $\mathrm{H}_{2} \mathrm{O}$ to form a hydrogen bonding, and as a result, the complex has an asymmetric structure of $\mathrm{H}_{2} \mathrm{O}$ relative to $\mathrm{X}^{-}$. For larger clusters, in addition to the interaction between the ions and the ligands, the ligand water molecules are also held together by networks of hydrogen bonding. The importance of the hydrogen bonding was also pointed out in the theoretical study on $\mathrm{H}^{-}\left(\mathrm{H}_{2} \mathrm{O}\right)_{n} \cdot{ }^{48}$ The optimal structure calculated for $n=1$ is similar to that for $\mathrm{X}^{-}\left(\mathrm{H}_{2} \mathrm{O}\right)$, and those for $n=2$ and 3 have hydrogen bondings not only between the $\mathrm{H}^{-}$ion and the ligands but also between the ligand pairs, as in the cases of hydrated halide ions. In the hydrated halide negative ions, the successive hydration energies for $n=2-5$ were found to be almost constant. This fact indicates that the formation of hydrogen bondings between the ligands has a substantial contribution in the hydration energies. Since the $\mathrm{Cu}^{-}$ion has the closed shell configuration as in the cases of the $\mathrm{X}^{-}$and $\mathrm{H}^{-}$ions, the hydrated $\mathrm{Cu}^{-}$ions are expected to have the similar geometrical structures to those for the latter ions. Therefore, the hydrogen bondings between the metal ion 
and the ligand molecules as well as between the ligand molecules may play an important role in the metal-ligand interaction in addition to the electrostatic interaction. This may be the reason for the observation that the successive hydration energies for $\mathrm{Cu}^{-}\left(\mathrm{H}_{2} \mathrm{O}\right)_{n}$ are almost constant up to $n=4$, as noted above in the case of hydrated halide ions.

\subsection{Hydration to the Copper Dimer and Its Negative Ion}

The photoelectron spectra of negative ions of copper dimer and its hydrate are shown in Figs. $3 \mathrm{f}$ and $3 \mathrm{~g}$. The spectrum of $\mathrm{Cu}_{2}{ }^{-}$is almost consistent with those reported previously by other authors: ${ }^{31-33}$ The first and second bands peaked at 0.88 and 2.79 $\mathrm{eV}$ correspond to the transitions from $\mathrm{Cu}_{2}{ }^{-} X^{2} \Sigma_{\mathrm{u}}{ }^{+}$to the neutral ground state, $\mathrm{Cu}_{2}$ $X^{1} \Sigma_{\mathrm{g}}{ }^{+}$, and the triplet excited state, $\mathrm{Cu}_{2} a^{3} \Sigma_{\mathrm{u}}{ }^{+}$, respectively. The spectrum of $\mathrm{Cu}_{2}{ }^{-}$ $\left(\mathrm{H}_{2} \mathrm{O}\right)$ exhibits two peaks at 1.28 and $2.82 \mathrm{eV}$ with a shoulder at $3.21 \mathrm{eV}$. As mentioned previously, the $\mathrm{Cu}^{-}\left(\mathrm{H}_{2} \mathrm{O}\right)_{4}$ ion could not be discriminated from $\mathrm{Cu}_{2}-\left(\mathrm{H}_{2} \mathrm{O}\right)$ by the pulsed mass gate, and as a result, the spectra may contain the bands attributed to the former ion. In fact, the spectral feature of the second band is almost the same as those of $\mathrm{Cu}^{-}\left(\mathrm{H}_{2} \mathrm{O}\right)_{4}$, and thus we concluded that this band is ascribed to the $\mathrm{Cu}^{-}$ $\left(\mathrm{H}_{2} \mathrm{O}\right)_{4}$ ion. Therefore, the first band at $1.28 \mathrm{eV}$ can be assigned to the transition to the neutral ground state, and the shoulder at $3.21 \mathrm{eV}$ may correspond to the transition to the excited state. The VDEs of $\mathrm{Cu}_{2}^{-}$and $\left.\mathrm{Cu}_{2}-\mathrm{H}_{2} \mathrm{O}\right)$ are plotted in Fig. 4. Both the first and the second bands are stabilized ca. $0.4 \mathrm{eV}$ by hydration, which is slightly larger than the stabilization for the first band for $\mathrm{Cu}^{-}(0.35 \mathrm{eV})$. As for the first band, this difference is expected to be mainly due to that of the hydration energies for the negative ions: The hydration energy for $\mathrm{Cu}_{2}^{-}$is larger than that for $\mathrm{Cu}^{-}$because of the polarization of the dimer anion.

\section{CONCLUDING REMARKS}

The technique of the negative-ion photoelectron spectroscopy has been applied for the first time to the hydrated metal atom clusters. We have measured the photoelectron spectra of $\mathrm{Cu}^{-}\left(\mathrm{H}_{2} \mathrm{O}\right)_{n}(n=0-4)$ and $\mathrm{Cu}_{2}^{-}\left(\mathrm{H}_{2} \mathrm{O}\right)_{n}(n=0$ and 1). The lowest bands in the spectra of $\mathrm{Cu}^{-}\left(\mathrm{H}_{2} \mathrm{O}\right)_{n}(n=1-3)$ are found to be assignable to the detached electrons from the $\mathrm{CuOH}^{-}\left(\mathrm{H}_{2} \mathrm{O}\right)_{n-1}$ ions, and the remaining bands are ascribed to the transitions to the neutral states derived from the ground ${ }^{2} S\left(3 d^{10} 4 s^{1}\right)$ and the excited ${ }^{2} D\left(3 d^{9} 4 s^{2}\right)$ states of the free $\mathrm{Cu}$ atom. Vertical detachment energies determined from the peak positions of the bands in the spectra show linear dependence on the number of water molecules both for the first and second bands. The energy diagram including the negative ion states and the ground and the excited states of the neutrals is constructed for $n=0-4$. The successive hydration energies for $\mathrm{Cu}^{-}\left(\mathrm{H}_{2} \mathrm{O}\right)_{n}$ are found to be almost constant at ca. $0.6 \mathrm{eV}$ from the energy diagram. The hydrogen bonding is expected to have a substantial contribution in the hydration energies, in addition to the electrostatic interaction. As for $\mathrm{Cu}_{2}^{-}$, the hydration energy is found to be slightly larger than that for $\mathrm{Cu}^{-}$because of the polarization. 


\section{Acknowledgments}

The authors wish to thank the members of the Equipment Development Center of Institute for Molecular Science for their contributions in constructing the experimental apparatus. We also thank Dr. A. Nakajima for giving valuable advice for developing the magnetic-bottle photoelectron spectrometer. The present work has been partly supported by a Grant-in-Aid for Scientific Research from the Ministry of Education, Science, and Culture.

\section{References}

1. M. H. Shen, J. W. Winniczek, and J. M. Farrar. J. Phys. Chem., 91, 6447 (1987).

2. M. H. Shen and J. M. Farrar. J. Phys. Chem., 93, 4386 (1989).

3. M. H. Shen and J. M. Farrar. J. Chem. Phys., 94, 3322 (1991).

4. S. G. Donnelly and J. M. Farrar. J. Chem. Phys., 98, 5450 (1993).

5. F. Misaizu, M. Sanekata, K. Tsukamoto, K. Fuke and S. Iwata. J. Phys. Chem., 96,8259 (1992).

6. F. Misaizu, M. Sanekata, K. Fuke, and S. Iwata. J. Chem. Phys., 100, 1161 (1994); K. Fuke, F. Misaizu, M Sanakata, K. Tsukamoto, and S. Iwata. Z. Phys., D 26, S180 (1993).

7. M. Sanekata, F. Misaizu, K. Fuke, K. Hashimoto, and S. Iwata. J. Am. Chem. Soc., (submitted).

8. I. V. Hertel, C. Huglin, C. Nitsch, and C. P. Schulz. Phys. Rev. Lett., 67, 1767 (1991).

9. C. P. Schulz, A. Gerber, C. Nitsch, and I. V. Hertel. Z Phys., D 20, 65 (1991).

10. F. Misaizu, K. Tsukamato, M. Sanekata and K. Fuke. Chem. Phys. Lett., 188, 241 (1992); K. Fuke, F. Misaizu, K. Tsukamato, and M. Sanekata. Physics and Chemistry of Finite Systems, edited by P. Jena, S. N. Khanna, and B. K. Rao (Kluwer, Dordrecht, 1992), Vol. II, p. 925.

11. E. Kochanski and E. Constantin. J. Chem. Phys., 87, 1661 (1987).

12. C. W. Bauschlicher, Jr. and H. Patridge. J. Phys. Chem., 95, 3946 (1991).

13. C. W. Bauschlicher, Jr. and H. Patridge.J. Phys. Chem., 95, 9694 (1991)

14. C. W. Bauschlicher, Jr., M. Sodupe, and H. Patridge.J. Chem. Phys., 96, 4453 (1992).

15. N. R. Kestner and S. Dhar. Large Finite Systems, edited by J. Jortner (Reidel, Dordrecht, 1987), pp. 209.

16. M. Marchi, M. Sprik, and M. L. Klein. Faraday Discuss. Chem. Soc., 85, 373 (1988).

17. C. W. Bauschlicher, Jr., S. R. Langhoff, H. Patridge, J. E. Rice, and A. Komornicki. J. Chem. Phys., 95, 5142 (1991).

18. R. N. Barnett and U. Landman. Phys. Rev. Lett., 70, 1775 (1993).

19. K. Hashimoto, S. He and K. Morokuma Chem. Phys. Lett., 206, 297 (1993).

20. G. Markovich, R. Giniger, M. Levin, and O. Cheshnovsky. J. Chem. Phys., 95, 9416 (1991); Z. Phys., D 20, 69 (1991).

21. G. Markovich, S. Pollack, R. Giniger, and O. Cheshnovsky. Z. Phys., D 26, 98 (1993).

22. G. Markovich, O. Cheshnovsky, and U. Kaldor J. Chem. Phys., 99, 6201 (1993).

23. W. C. Wiley and I. H. McLaren. Rev. Sci. Instrum., 26, 1150 (1955).

24. P. Kruit and F. H. Read. J. Phys., E 16, 313 (1983).

25. O. Cheshnovsky, S. H. Yang, C. L. Pettiette, M. J. Craycraft and R. E. Smally. Rev. Sci. Instrum., 58, 2131 (1987).

26. H. Hotop, R. A. Bennett, and W. C. Lineberger. J. Chem. Phys., 58, 2373 (1973).

27. H. Haberland, H.-G. Schindler, and D. R. Worsnop. Ber. Bunsenges. Phys. Chem., 88, 270 (1984); H. Haberland, C. Ludewigt, H.-G. Schindler, and D. R. Worsnop. Surface Sci., 156, 157 (1985).

28. M. Knapp. O. Echt, D.Kreisle, and E. Recknagel. J. Chem. Phys., 85, 636 (1986); J. Phys. Chem., 91, 2601 (1987).

29. L. A. Posey and M. A. Johnson. J. Chem. Phys., 89, 4807 (1988); L. A. Posey, P. J. Campagnola, and M. A. Johnson. J. Phys. Chem., 93, 1178 (1989).

30. T. Kondow. J. Phys. Chem., 91, 1307 (1987); F. Misaizu, T. Kondow, and K. Kuchitsu. Chem. Phys. Lett., 178, 369 (1991).

31. J. Ho, K. M. Ervin, and W. C. Lineberger. J. Chem. Phys., 93, 6987 (1990).

32. O. Cheshnovsky, K. J. Taylor, J. Conceicao, and R. E. Smally. Phys. Rev. Lett., 64, 1785 (1990); K. J. Taylor, C. L. Pettiette-Hall, O. Cheshnovsky, and R. E. Smalley. J. Chem. Phys., 96, 3319 (1992). 
33. C.-Y. Cha, G. Ganteför, and W. Eberhardt. J. Chem. Phys., 99, 6308 (1993); Z. Phys., D 26, 307 (1993).

34. R. J. Celotta, R. A. Bennett, and J. L. Hall. J. Chem. Phys., 60, 1740 (1974).

35. H. Hotop, T. A. Patterson, and W. C. Lineberger. Bull. Am. Phys. Soc., 18, 810 (1973).

36. C. E. Moore. Atomic Energy Levels, Natl. Stand. Ref. Data Ser., NBS 35 (National Bureau of Standards, Washington, D.C., 1971) Vol. II.

37. M. Trkula and D. O. Haris. J. Chem. Phys., 79, 1138 (1983).

38. C. N. Jarman. W. T. M. L. Fernando, and P. F. Bernath. J. Mol. Spectrosc., 144, 286 (1990); 145, $151(1991)$.

39. C. W. Bauschlicher. Jr.. Int. J. Quantum Chem: Quantum Chem. Symp., 20. 563 (1986).

40. Y. Mochizuki, T. Takada, and A. Murakami. Chem. Phys. Lett., 185, 535 (1991).

41. J. V. Coe, G. H. Lee, J. G Eaton, S. T. Arnold, H. W. Sarkas, K. H. Bowen, C. Ludewigt, H. Haberland, and D. R. Worsnop. J. Chem. Phys., 92, 3980 (1990).

42. C. W. Bauschlicher, Jr.. J. Chem. Phys., 84, 260 (1986).

43. P. Kebarle. Ann. Rev. Phys. Chem., 28, 445 (1977); M. Ashadi, R. Yamdagni, and P. Kebarle. J. Phys. Chem., 74, 1475 (1970).

44. R. G. Keesee, N. Lee, and A. W. Castleman, Jr.. J. Chem. Phys., 73, 2195 (1980).

45. J. E. Combariza, N. R. Kestner, and J. Jortner. J. Chem. Phys., 100, 2851 (1994).

46. CRC Handbook of Chemistry and Physics, 59th ed., ed by R. C. Weast (CRC press, Florida, 1978), pp. F-213.

47. A. Bondi. J. Phys. Chem., 68, 441 (1964).

48. S. S. Xantheas and T. H. Dunning, Jr.. J. Phys. Chem., 96, 7505 (1992). 